\title{
Biossorção de metais pesados pela casca de ovo de galinhas poedeiras
}

\begin{abstract}
A remoção de íons metálicos é uma tarefa difícil devido ao elevado custo dos métodos de tratamento, o que tem contribuído para a intensificação de pesquisa por materiais adsorventes alternativos de baixo custo e que podem ser reutilizáveis, tendo seu valor agregado ao processo de adsorção. Assim, com este trabalho objetivou-se estudar o potencial de utilização da casca de ovo como biossorvente alternativo para remoção de íons metálicos em águas residuárias. Especificamente determinou-se as isotermas de adsorção para os íons metálicos cobre (II), cromo (III), níquel (II) e zinco (II), utilizando-se os modelos de Langmuir e Freundlich. Para a realização dos estudos, soluções contendo íons metálicos em diversas concentrações foram adicionadas a cascas de ovos de galinhas poedeiras, mantidas sob agitação orbital por 24 horas a 25 ㄷ e, posteriormente filtradas para determinação, em espectrofotômetro de absorção atômica, a concentração de equilíbrio dos íons. De acordo com os resultados, conclui-se que tanto o modelo de Langmuir quanto o modelo de Freundlich descreveram adequadamente a adsorção dos íns cobre, cromo, níquel e zinco pela casca de ovo moída; a capacidade máxima de adsorção para os íons de cobre zinco, níquel e cromo, foi de 25,4291; 6,7354; 9,7928 e 6,7283 mg g-1, respectivamente; a sequência de afinidade na adsorção dos íons metálicos foi $\mathrm{Cu}>\mathrm{Ni}>\mathrm{Zn} \cong \mathrm{Cr}$; a casca de ovo apresentou potencial para a remoção dos íons metálicos, podendo ser utilizada em sistemas de tratamento de efluentes.
\end{abstract}

Palavras-chave: Adsorção; Isoterma; Lagmuir; Biosorvente.

\section{Biosorption of heavy metals by the eggshell of laying hen}

\begin{abstract}
The removal of metallic ions is a difficult task due to the high cost of the treatment methods, which has contributed to the intensification of research by alternative adsorbent materials of low cost and that can be reusable, having their added value to the adsorption process. Thus, in this study aimed the potential use of eggshell as an alternative biosorbent for the removal of metallic ions in wastewater. Specifically, the adsorption isotherms for the copper (II), chromium (III), nickel (II) and zinc (II) metal ions were determined using the Langmuir and Freundlich models. To perform the studies, solutions containing metal ions in various concentrations were added to eggshells of laying hens, kept under orbital agitation for 24 hours at $25 \circ \mathrm{C}$ and, subsequently filtered for determination in atomic absorption spectrophotometer, the equilibrium concentration of ions. According to the results, it is concluded that both the Langmuir model and the Freundlich model adequately described the adsorption of the copper, chromium, nickel and zinc ions by the ground egg shell; the maximum adsorption capacity for zinc, nickel and chromium copper ions was $25.4291 ; 6,7354 ; 9.7928$ and $6.7283 \mathrm{mg} \mathrm{g}-1$, respectively; the affinity sequence in the adsorption of the metal ions was $\mathrm{Cu}>\mathrm{Ni}>\mathrm{Zn} \cong \mathrm{Cr}$; the eggshell presented potential for the removal of metallic ions, and it can be used in effluent treatment systems.
\end{abstract}

Keywords: Adsorption; Isoterma; Lagmuir; Biosorbent.

Topic: Desenvolvimento, Sustentabilidade e Meio Ambiente

Reviewed anonymously in the process of blind peer
Received: 10/08/2018

Approved: 24/09/2018
Débora Astoni Moreira (ic

Instituto Federal Goiano, Brasil

http://lattes.cnpq.br/0892554192927049

http://orcid.org/0000-0002-8658-1269

debora.astoni@ifgoiano.edu.br

José Antonio Rodrigues de Souza (it)

Instituto Federal Goiano, Brasil

http://lattes.cnpq.br/1637300776838940

http://orcid.org/0000-0003-3024-9424

jose.antonio@ifgoiano.edu.br

\section{Éllen Lemes Silva (iD)}

Instituto Federal Goiano, Brasil

http://lattes.cnpq.br/2020996967548069

http://orcid.org/0000-0001-5649-5055

ellen cbba@hotmail.com
Janine Mesquita Gonçalves (iD) Instituto Federal Goiano, Brasil http://lattes.cnpq.br/6297254122829148

http://orcid.org/0000-0003-1367-4488

janine.goncalves@ifgoiano.edu.br

Diego César Veloso Rezende (iD

Instituto Federal Goiano, Brasil

http://lattes.cnpq.br/2390623769547865

http://orcid.org/0000-0001-6176-0220

diegoformiga@yahoo.com.br

Walisson Marques Oliveira (iD)

Instituto Federal Goiano, Brasil

http://lattes.cnpq.br/7052217868475846

http://orcid.org/0000-0002-4615-8335

walissonmo.msn@hotmail.com
Wesley Anderson Siqueira Ribeiro (DD Instituto Federal Goiano, Brasil http://lattes.cnpq.br/4063527816946300 http://orcid.org/0000-0003-4056-9798 wesleyk13anderson@hotmail.com

João Gabriel Felismino Rezende Instituto Federal Goiano, Brasil http://lattes.cnpq.br/5949610566978863 joaogabrielsta1209@gmail.com

\section{Referencing this:}

MOREIRA, D. A.; SOUZA, J. A. R.; SILVA, É. L.; GONÇALVES, J. M.; REZENDE, D. C. V.; OLIVEIRA, W. M.; RIBEIRO, W. A. S.; REZENDE, J. G. F.. Biossorção de metais pesados pela casca de ovo de galinhas poedeiras. Revista Ibero Americana de Ciências Ambientais, v.9, n.7, p.289-295, 2018. DOI: http://doi.org/10.6008/CBPC21796858.2018.007.0027 


\section{INTRODUÇÃO}

O elevado crescimento industrial e agropecuário ocorrido nos últimos anos têm sido um dos principais responsáveis pelo comprometimento da qualidade dos recursos naturais, tanto pelo tratamento e disposição inadequada dos efluentes industriais, como pela aplicação indiscriminada de insumos agrícolas, os quais propiciam aporte de poluentes nos solos e cursos de água. Dentre os vários contaminantes do meio ambiente, os metais pesados merecem atenção especial, uma vez que, são bioacumuladores e não degradáveis (SILVA, 2013; NASCIMENTO, 2015; BARROS, 2017).

Íons como o cobre, níquel, cromo e zinco estão entre os poluentes mais tóxicos presentes em efluentes provenientes de processos industriais. O cobre, mesmo em baixas concentrações, pode se depositar no cérebro, pele, fígado e pâncreas causando sérios efeitos toxicológicos nos seres humanos, enquanto que, o níquel pode causar dermatites, asma, náuseas e câncer (AL BAKHEET et al., 2013). O cromo, dependendo da forma como se encontra, em doses elevadas pode causar ulceração do septo nasal, inflamação da mucosa nasal, bronquite crônica e enfisema (GOMES et al., 2005). Já o excesso de zinco está associado à supressão da resposta imune, diminuição da lipoproteína de alta densidade (HDL) e à redução das concentrações de cobre no plasma (CRUZ et al., 2011).

Assim, diversos métodos de remoção de metal pesado em efluentes têm sido estudados, tais como a precipitação, filtração por membrana/osmose, eletrodeposição, troca iônica, oxidação/redução e adsorção, sendo a adsorção, a operação de separação mais efetiva no tratamento de águas residuárias (PINTO et al., 2013; MARTINS et al., 2015; SUZAKI et al., 2015). Todavia, estes métodos são muitas vezes restritos por inviabilidade técnica e/ou econômica, especialmente quando os metais estão dissolvidos em grandes volumes de água e em concentrações relativamente baixas (ZHANG et al., 2014).

Dessa forma, a utilização de resíduos agroindustriais na remoção de poluentes em compartimentos ambientais, conhecida como biossorção, vem despertado grande interesse (FENG et al., 2011), uma vez que este processo é baseado na capacidade de ligação entre o metal e o adsorvente natural, que pode ser constituído por biomassa, bactérias, fungos e algas, tendo como fator chave em seu sucesso, um material adsorvente que proporcione além da alta capacidade de remoção, um baixo custo (SILVA et al., 2014).

Considerando-se a elevada toxicidade dos metais pesados e a necessidade de buscar materiais de baixo custo e alta eficiência na sua remoção dos efluentes, objetou-se, com este trabalho, estudar o potencial de remoção pela casca de ovo de galinhas poedeiras dos íons metálicos cobre (II), cromo (III), níquel (II) e zinco (II) presentes em águas residuárias, por meio de isotermas de adsorção.

\section{MATERIAIS E MÉTODOS}

O estudo foi conduzido no Instituto Federal Goiano - Campus Urutaí, em Urutaí/GO, localizado a $17^{\circ} 29^{\prime} 6^{\prime \prime} \mathrm{S}, 48^{\circ} 12^{\prime} 27^{\prime \prime} \mathrm{O}$ e altitude de $712 \mathrm{~m}$, compreendendo três períodos distintos, entre dezembro de 2017 a março de 2018, sendo todas as amostras realizadas em triplicatas. 
Utilizou-se como biossorvente natural cascas de ovos de galinhas poedeiras da raça Plymouth Rock

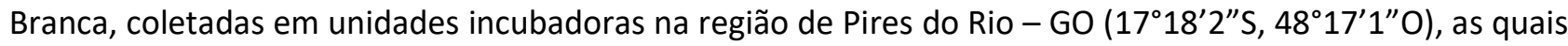
foram conduzidas ao Laboratório de Pesquisa e Análises Químicas do IFGoiano - Campus Urutaí, sendo, posteriormente, secas ao ar, trituradas, passadas em peneiras de 0,074 $\mathrm{mm}$ e, caracterizada química e fisicamente. Na Tabela 1 estão apresentadas as características das cascas de ovos utilizadas nos ensaios experimentais.

Tabela 1: Características químicas e físicas das cascas de ovos moídas utilizadas nos ensaios experimentais.

\begin{tabular}{|l|l|l|l|}
\hline Características & Concentração & Características & Concentração \\
\hline Umidade $($ dag kg-1) & 13,53 & Carbono Orgânico $\left(\right.$ dag kg$\left.^{-1}\right)$ & 0,69 \\
\hline $\mathrm{pH}$ em água & 9,02 & Matéria Orgânica $\left(\mathrm{dag} \mathrm{kg}^{-1}\right)$ & 1,19 \\
\hline $\mathrm{pH}$ em CaCl & 7,22 & Cobre $\left(\mathrm{mg} \mathrm{kg}^{-1}\right)$ & 5,84 \\
\hline Condutividade Elétrica $(\mathrm{uS} \mathrm{cm}-1)$ & 226,80 & Cromo $\left(\mathrm{mg} \mathrm{kg}^{-1}\right)$ & $\mathrm{nd}$ \\
\hline Nitrogênio total $(\mathrm{dag} \mathrm{kg}$ & & \\
\hline Sólidos Totais $\left(\mathrm{mg} \mathrm{kg}^{-1}\right)$ & 9,17 & Níquel $\left(\mathrm{mg} \mathrm{kg}^{-1}\right)$ & 7,57 \\
\hline
\end{tabular}

Sendo: nd abaixo do limite de detecção.

Na condução dos ensaios de adsorção, foram preparadas soluções contendo o íon metálico a ser avaliado nas concentrações iguais a $25,50,75,100,150,200,250,500,750$ e $1000 \mathrm{mg} \mathrm{L}^{-1}$ e com o pH igual a 5 para os íons cobre, cromo e zinco e, igual a 6 para o íon níquel. Uma alíquota de $20 \mathrm{~mL}$ da solução contendo o metal e 0,5 g de casca de ovo moída foram transferidos para erlenmeyers com capacidade volumétrica de $125 \mathrm{~mL}$, onde ficaram sob agitação orbital de $100 \mathrm{rpm}$, a uma temperatura de 25 드, por um período de 24 horas. Posteriormente, estas misturas foram centrifugadas a $1258 \mathrm{~g}$ (FRC) por 15 minutos e filtradas à vácuo, obtendo-se a solução de equilíbrio.

A concentração dos íons metálicos na solução de equilíbrio foi determinada por meio de espectrofotometria de absorção atômica em chamas, sendo a quantidade de íon adsorvido, obtida pela diferença entre a concentração inicial e aquela obtida na solução de equilíbrio. Para descrever e avaliar o comportamento do processo de biossorção foram utilizados os modelos de Langmuir (Equação 1) e Freundlich (Equação 2), conforme descrito por Nascimento et al. (2014).

$$
\theta=\frac{\theta_{\mathrm{m}} * \mathrm{~K} * \mathrm{C}_{\mathrm{eq}}}{\left(1+\mathrm{K} * \mathrm{C}_{\mathrm{eq}}\right)}
$$

(Equação 1)

em que:

$\theta=$ quantidade adsorvida $\left(\mathrm{mg} \mathrm{g}^{-1}\right)$; $\theta \mathrm{m}=$ capacidade máxima de adsorção $\left(\mathrm{mg} \mathrm{g}^{-1}\right)$; $\mathrm{K}=$ coeficiente relacionado à energia de ligação $\left(\mathrm{L} \mathrm{mg}^{-1}\right)$; Ceq. = concentração do íon na solução $\left(\mathrm{mg} \mathrm{L}^{-1}\right)$.

$$
\theta=\mathrm{k}_{\mathrm{f}} \mathrm{C}_{\mathrm{eq}} \cdot \frac{1}{\mathrm{n}}
$$

em que: $\theta=$ quantidade adsorvida $\left(\mathrm{mg} \mathrm{g}^{-1}\right)$; $\mathrm{k}_{\mathrm{f}}=$ constante de Freundlich $\left(\mathrm{mg} \mathrm{g}^{-1}\right)$ Ceq. = concentração do íon na solução $\left(\mathrm{mg} \mathrm{L}^{-1}\right)$. $\mathrm{n}=$ parâmetro empírico 


\section{RESULTADOS}

Os modelos de isotermas de adsorção são fundamentais para verificar a eficiência dos adsorventes em relação a sua capacidade de adsorção por meios das interações com o adsorbato e, assim, poder determinar a melhor aplicação do adsorvente (FERREIRA et al, 2015). Na Figura 1 estão apresentadas as isotermas de adsorção dos íons metálicos estudados conforme modelo proposto por Langmuir e Freundlich, obtida pela relação entre a quantidade de metal adsorvida e a concentração de equilíbrio.

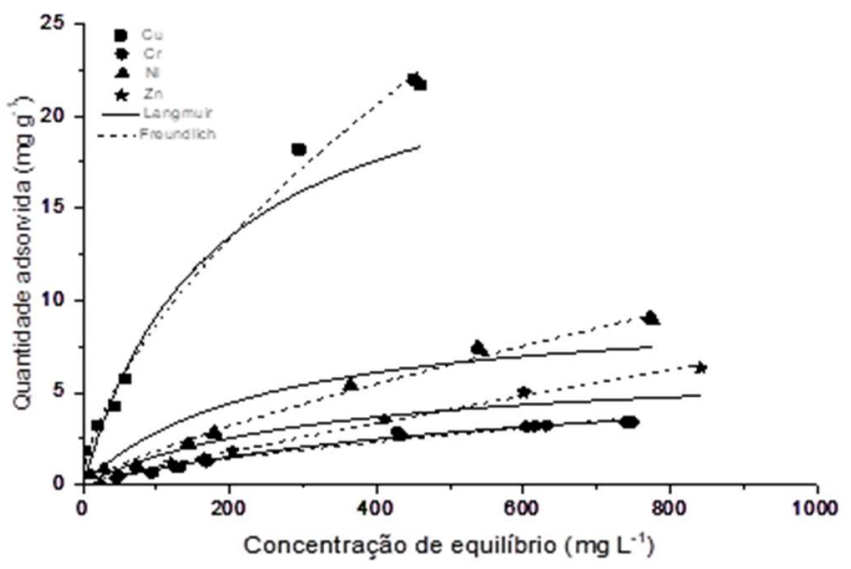

Figura 1: Isoterma de adsorção dos íons metálicos para a casca de ovo moída ajustadas conforme modelo proposto por Langmuir e Freundlich.

Entre os diversos modelos que descrevem a adsorção, os mais comumente citados na literatura são aqueles propostos por Langmuir e por Freundlich. A teoria de Langmuir se baseia no fato da adsorção ocorrer em sítios uniformes com recobrimento em monocamada e afinidade iônica independentemente da quantidade de material adsorvido (ATKINS, 1994). O modelo de Freundlich considera a não uniformidade das superfícies reais e considera que os íons metálicos são infinitamente acumulados na superfície do adsorvente e ocorre em multicamadas (YAMAMURA et al., 2005). Assim, estão apresentados os valores dos parâmetros obtidos para os modelos de Langmuir e Freundlich, conforme Tabela 2.

Tabela 2: Parâmetros dos modelos de Langmuir e Freundlich para adsorção de íons metálicos pela casca de ovo moída.

\begin{tabular}{|c|c|c|c|c|}
\hline \multirow[t]{2}{*}{ Parâmetros } & \multicolumn{4}{|l|}{ Íons metálicos } \\
\hline & Cobre & Cromo & Níquel & zinco \\
\hline & \multicolumn{4}{|l|}{ Langmuir } \\
\hline$\theta_{\mathrm{m}}\left(\mathrm{mg} \mathrm{g}^{-1}\right)$ & $25,4291 \pm 2,0855$ & $6,7283 \pm 0,4244$ & $9,7928 \pm 1,1058$ & $6,7354 \pm 1,0929$ \\
\hline $\mathrm{K}\left(\mathrm{L} \mathrm{mg}^{-1}\right)$ & $0,0056 \pm 0,0015$ & $0,0015 \pm 0,0002$ & $0,0041 \pm 0,0012$ & $0,0030 \pm 0,0011$ \\
\hline \multirow[t]{2}{*}{$\mathrm{R}^{2}$} & 0,9244 & 0,9897 & 0,9186 & 0,9014 \\
\hline & \multicolumn{4}{|l|}{ Freundlich } \\
\hline $\mathrm{Kf}\left(\mathrm{mg} \mathrm{g}^{-1}\right)$ & $0,4945 \pm 0,0625$ & $0,0361 \pm 0,0077$ & $0,0508 \pm 0,0073$ & $0,0162 \pm 0,0021$ \\
\hline $\mathrm{N}$ & $1,6061 \pm 0,0599$ & $1,4357 \pm 0,0711$ & $1,2793 \pm 0,0377$ & $1,1230 \pm 0,0263$ \\
\hline $\mathrm{R}^{2}$ & 0,9923 & 0,9757 & 0,9924 & 0,9948 \\
\hline
\end{tabular}

Sendo $\theta \mathrm{m}=$ capacidade máxima de adsorção; $\mathrm{K}=$ coeficiente relacionado à energia de ligação $\left(\mathrm{L} \mathrm{mg}^{-1}\right) ; \mathrm{R}^{2}=$ coeficiente de determinação; $\mathrm{k}_{\mathrm{f}}=$ constante de Freundlich $\left(\mathrm{mg} \mathrm{g}^{-1}\right) ; \mathrm{n}=$ parâmetro empírico, constante.

\section{DISCUSSÃO}

De acordo com a Figura 1, verifica-se que a adsorção dos íons estudados aumentou com incrementos nas concentrações do adsorbato. De acordo com McCable et al. (2000), as isotermas obtidas podem ser classificadas como do tipo favorável, uma vez que apresentam leve concavidade para baixo e parâmetro de 
equilíbrio (RL) entre 0 e 1 . Ainda segundo estes autores, isotermas côncavas são favoráveis ao processo de adsorção, possibilitando extrair quantidades relativamente altas, mesmo em baixos níveis de concentração do adsorvato. Também, conforme classificação de Giles (GILES et al., 1974), as isotermas obtidas pertencem ao grupo L e subgrupo 1, refletindo alta afinidade dos cátions metálicos com um sítio específico e, cujo formato da curvatura inicial voltada para baixo ocorre devido a diminuição da disponibilidade dos sítios ativos (LIMA, 2013).

De acordo com a Tabela 2, verifica-se que tanto o modelo proposto por Langmuir como aquele proposto por Freundlich se ajustaram aos dados experimentais, apresentando coeficientes de correlação $\left(R^{2}\right)$ próximos de 1. De modo geral, o modelo de Freundlich foi o apresentou melhor ajuste, apresentando os maiores coeficientes de correlação.

Verifica-se, ainda na Tabela 2, que a capacidade máxima de adsorção dos íons metálicos pela casca de ovo moída, obtidas conforme modelo proposto por Langmuir, foi de 25,4291; 6,7283; 9,7928 e 6,7354 mg $\mathrm{g}^{-1}$ para os íons cobre, cromo, níquel e zinco, respectivamente. Tanto a capacidade máxima de adsorção, como o parâmetro relacionado a energia de ligação, obtidos pelo modelo de Langmuir, foi maior para o cobre, seguida pelo níquel, zinco e cromo, apresentando a seguinte sequência de afinidade $\mathrm{Cu}>\mathrm{Ni}>\mathrm{Zn} \cong \mathrm{Cr}$. Dessa forma, verifica-se que a adsorção foi influenciada pela eletronegatividade dos íons metálicos, seguindo a mesma sequência da escala de eletronegatividade de Pauling ( $\mathrm{Cu}=1,9 ; \mathrm{Ni}=1,8 ; \mathrm{Zn}=1,6$ e $\mathrm{Cr}=1,6)$.

De acordo com Barros (2012), a eletronegatividade está relacionada à atração entre os elétrons e o núcleo de uma espécie. Assim, essa grandeza está intimamente relacionada ao tamanho do raio iônico porque, quanto menor o seu tamanho, maior é a força de atração entre os elétrons e o núcleo porque a distância entre eles será menor. Portanto, quanto maior a eletronegatividade, maior a afinidade entre os íons metálicos e $o$ adsorvente.

De acordo com Malik (2003), ao se analisar os parâmetros do modelo proposto por Freundlich, verifica-se sequência de afinidade dos íns metálicos pela casca de ovo moída semelhante àquela obtida pelo modelo de Langmuir, porém com preferência do íon níquel em relação ao zinco. Também, conforme Malik (2003) e Clark (2010) observa-se que os sítios são heterogêneos energeticamente e que a isoterma de adsorção dos metais é do tipo favorável.

Ao se comparar os resultados da capacidade de adsorção dos íons metálicos obtidas neste estudo aos diversos estudos de adsorção, tais como aqueles desenvolvidos por Barros (2012), Lopes (2016), Argun et al. (2007), Fagundes-Klen et al. (2007) e Muataz et al. (2010), verificou-se que a casa de ovo moída apresentou capacidade máxima de adsorção de íons metálicos superior ao carvão ativado e outros biossorventes naturais. Assim, de modo geral, verifica-se que a casca de ovo moída pode ser utilizada para o processo de remoção dos íons metálicos, substituindo outros materiais utilizados, apresentando eficácia superior, mesmo em baixas concentrações, sendo, portanto, uma alternativa econômica em relação ao tratamento convencional. 


\section{CONCLUSÕES}

De acordo com as condições experimentais, pode se concluir que tanto o modelo de Langmuir quanto o modelo de Freundlich descrevem adequadamente a adsorção dos íons cobre, cromo, níquel e zinco pela casca de ovo moída; a capacidade máxima de adsorção para os íons de cobre zinco, níquel e cromo, foi de 25,4291; 6,7354; 9,7928 e 6,7283 $\mathrm{mg} \mathrm{g}^{-1}$, respectivamente; a sequência de afinidade na adsorção dos íons metálicos foi $\mathrm{Cu}>\mathrm{Ni}>\mathrm{Zn} \cong \mathrm{Cr}$; a casca de ovo apresentou potencial para a remoção dos íons metálicos, podendo ser utilizada em sistemas de tratamento de efluentes.

\section{REFERÊNCIAS}

AL BAKHEET, S. A.; ATTAFI, I. M.; MAAYAH, Z. H.; ABD-ALLAH, A. R.; ASIRI, Y. A.; KORASHY, H. M.. Effect of long-term human exposure to environmental heavy metals on the expression of detoxification and DNA repair genes.

Environmental Pollution (Barking, Essex: 1987), v.181, p.226-32, 2013. DOI:

http://doi.org/10.1016/j.envpol.2013.06.014

ARGUN, M. E.; DURSUN, S.; OZDEMIR, C.; KARATAS, M. Heavy metal adsorption by modified oak sawdust: Thermodynamics and kinetics. Journal of hazardous materials, v.141, n.1, p.77-85. 2007. DOI:

http://doi.org/10.1016/j.jhazmat.2006.06.095

ATKINS, P. W.. Physical chemistry. 5 ed. Oxford: Oxford University Press, 1994.

BARROS, A. M.. Bioadsorção e dessorção dos íons Cd2+, $\mathrm{Cu} 2+, \mathrm{Ni2}+, \mathrm{Pb2}+$ e $\mathrm{Zn2}+$ pela macrófita aquática azolla pinnata. Dissertação (Mestrado em Engenharia Química) Universidade Estadual de Campinas, Campinas, 2012.

BARROS, D. C.; CARVALHO, G.; RIBEIRO, M. A.. Processo de biossorção para remoção de metais pesados por meio de resíduos agroindustriais: uma revisão. Revista Biotecnologia \& Ciência, v.6, n.1, p.01-15, 2017.

CLARK, H. L. M.. Remoção de fenilalanina por adsorvente produzido a partir da torta prensada de grãos defeituosos de café. Dissertação (Mestrado em Ciência de Alimentos) Universidade Federal de Minas Gerais, Belo Horizonte, 2010.

CRUZ, J. B. F.; SOARES, H. F.. Uma revisão sobre o zinco. Ensaios e Ciência: Ciências Biológicas, Agrárias e da Saúde, , Campo Grande, v.15, n.1, p.207-222, 2011.

FAGUNDES-KLEN, M. R.; FERRI, P.; MARTINS, T. D.; TAVARES, C. R. G.; SILVA, E.. Equilibrium study of the binary mixture of cadmium-zinc ions biosorption by the Sargassum filipendula species using adsorption isotherms models and neural network. Biochemical Engineering Journal, ValparaísoChile, v.34, n.22, p.136-146, 2007. DOI: http://dx.doi.org/10.4067/S0717-34582007000400007

FENG, S.; HUANG, J.; WANG, J.. Loss of the Polycomb group gene polyhomeotic induces non-autonomous cell overproliferation. EMBO Rep., v.12, n.2, p.157-163, 2011.

FERREIRA, P. P. L.; BRAGA, R. M.; TEODORO, N. M. A.; MELO, V. R. M.; MELO, D. M. A.; MELO, M. A. F.. Adsorção de Cu 2+ e $\mathrm{Cr} 3+$ em efluentes líquidos utilizando a cinza do bagaço da cana-de-açúcar. Cerâmica, São Paulo, v.61. n.360, 2015. DOI: http://dx.doi.org/10.1590/0366-69132015613601945

GILES, C. H.; SMITH, D.; HUITSON, A.. A general treatment and classification of the solute adsorption isotherm. I. Theoretical. Journal Colloid and Interface Science, v.47, n.3, p.755-765, 1974. DOI: http://dx.doi.org/10.1016/00219797(74)90252-5

GOMES, M. R.; ROGERO, M. M.; TIRAPEGUI, J..

Considerações sobre cromo, insulina e exercício físico. Revista Brasileira de Medicina do Esporte, v.11, n.5, p.262266, 2005.

LIMA, L. C. C.. Isotermas de adsorção no estudo do comportamento de cobre e chumbo em solos originais e tratados para remoção de matéria orgânica. Dissertação (Mestrado em Química) - Instituto de Química, Brasília, 2013.

LOPES, R. P. F.. Remoção de cobre em efluente sintético por adsorção. Monografia (Graduação em Química) Universidade Federal do Rio Grande do Norte, Natal, 2016.

MALIK, P. K.. Use of activated carbons prepared from sawdust and rice-husk for adsorption of acid dyes: a case study of Acid Yellow 36. Dyes and Pigments, v.56, n.3, p.239-249, 2003. DOI: http://dx.doi.org/10.1016/S01437208(02)00159-6

MARTINS, W. A. M.; OLIVEIRA, A. M. B. M.; MORAIS, C. E. P.; COELHO, L. F. O.; MEDEIROS, J. F.. Reaproveitamento de resíduos agroindustriais de casca banana para tratamento de efluentes. Revista Verde de Agroecologia e Desenvolvimento Sustentável, Pombal, v.10, n.1, p.96-102, 2015. DOI: http://doi.org/10.18378/rvads.v10i1.3361

MCCABE, W. L.; SMITH, J. C.; HARRIOT, P.. Unit Operations of Chemical Engineering. 6 ed. McGraw-Hill Book Company, 2000.

MUATAZ, A. A.; OMER, Y. B.; BASSAM, S. T.; ALAADIN, A. B.; MAZEN, K.; MAMDOUH, A.; MOHAMMED, F.; FARAJ, A. A.. Removal of Chromium (III) from Water by Using Modified and Nonmodified Carbon Nanotubes. Journal of Nanomaterials, p.9, 2010. DOI: http://dx.doi.org/10.1155/2010/232378 
NASCIMENTO, R. F.; LIMA, A. C. A; VIDAL, C. B.; MELO D. Q.; RAULINO, G. S. C.. Adsorção: aspectos teóricos e aplicações ambientais. Fortaleza: Imprensa Universitária, 2014.

NASCIMENTO, J. M.. Estudo da remoção do íon cobre por meio de biossorção usando biomassa de levedura (Saccharomyces cerevisiae). Dissertação (Mestrado em Tecnologia de Processos Químicos e Bioquímicos) Universidade Federal do Rio de Janeiro, Rio de Janeiro, 2015.

PINTO, M. V. S.; SILVA, D. L.; SARAIVA, A. C. F.. Obtenção e caracterização de carvão ativado de caroço de buriti (Mauritia flexuosa L. f.) para a avaliação do processo de adsorção de cobre (II). Acta Amazônica, v.43, n.1, p.73-80, 2013. DOI: http://dx.doi.org/10.1590/S0044$\underline{59672013000100009}$

SILVA, J. L. B. C.; PEQUENO, O. T. B. L.; ROCHA, L. K. Y. S.; ARAÚJO, E. C. O. A.; MARCIEL, T. A. R.; BARROS, A. J. M. B..
Biossorção de metais pesados: uma revisão. Revista Saúde e Ciência, v.3, n.3, p.137-149, 2014.

SILVA, L. B. S.. Emprego de adsorventes oriundos da casca de arroz na remoção de cobre em efluentes aquosos.

Dissertação (Mestrado em Química) - Universidade Federal da Bahia, 2013.

SUZAKI, P. Y. R. M. M.; BERGAMASCO, R.; FAGUNDES-KLEN, M. R.; KLEINÜBING, S. J.; HONORIO, J. F.. Estudo do equilíbrio de biossorção dos íons $\mathrm{Cu}^{2+} \mathrm{e} \mathrm{Ni}^{2+}$ em sistema batelada pelo resíduo da extração do alginato da alga sargassum filipendul. In: CONGRESSO BRASILEIRO DE SISTEMAS PARTICULADOS, 37. Anais. UFSCAR, 2015. DOI: http://doi.org/10.5151/ENEMP2015-PS-444

YAMAMURA, A. P. G.; YAMAURA, M.. Estudo da cinética e das isotermas de adsorção de U pelo bagaço de cana-deaçúcar. In: INTERNATIONAL NUCLEAR ATLANTIC CONFERENCE/INAC. Anais. Santos, 2005.

A CBPC - Companhia Brasileira de Produção Científica (CNPJ: 11.221.422/0001-03) detém os direitos materiais desta publicação. Os direitos referem-se à publicação do trabalho em qualquer parte do mundo, incluindo os direitos às renovações, expansões e disseminações da contribuição, bem como outros direitos subsidiários. Todos os trabalhos publicados eletronicamente poderão posteriormente ser publicados em coletâneas impressas sob coordenação da Sustenere Publishing, da Companhia Brasileira de Produção Científica e seus parceiros autorizados. Os (as) autores (as) preservam os direitos autorais, mas não têm permissão para a publicação da contribuição em outro meio, impresso ou digital, em português ou em tradução. 